\title{
Fetal Cardiovascular and Catecholamine Responses to Hypoxemia after Chemical Sympathectomy
}

\author{
ALAN B. LEWIS, ${ }^{(24)}$ WENDY J. WOLF, AND WILLIAM SISCHO \\ Divison of Cardiology, Childrens Hospital of Los Angeles and the Department of Pediatrics, USC School of \\ Medicine, Los Angeles, California USA
}

\begin{abstract}
Summary
Chemical sympathectomy was performed in fetal lambs in utero by daily intravenous administration of 6-hydroxydopamine (6HD) until a total dose of $60-70 \mathrm{mg} / \mathrm{kg}$ was reached. The completeness of adrenergic denervation was confirmed by the absence of any cardiovascular response to tyramine infusion. Baseline plasma catecholamine concentrations in normoxemic, sympathectomized fetuses were slightly higher than controls but the differences were not statistically significant. The concentration of norepinephrine (NE) was $313 \pm 73 \mathrm{pg} / \mathrm{ml}$ after $6 \mathrm{HD}$ administration compared with $259 \pm 25 \mathrm{pg} / \mathrm{ml}$ in control animals. Similarly, the concentration of epinephrine (E) was $39 \pm 15 \mathrm{pg} /$ $\mathrm{ml}$ (6HD) versus $21 \pm 4 \mathrm{pg} / \mathrm{ml}$ (control). These mildly elevated catecholamine levels were accompanied by a small but significant increase in resting blood pressure (BP) $(P<0.05)$. Heart rate (HR), however, was no different from control. Hypoxemia induced a marked increase in plasma catecholamines in control animals (NE, $2416 \pm 419 \mathrm{pg} / \mathrm{ml}$ and $\mathrm{E}, 2017 \pm 749 \mathrm{pg} / \mathrm{ml}$ ) along with hypertension and bradycardia. Sympathectomized fetuses maintained a profound NE response to hypoxemia (NE, $1550 \pm$ $261 \mathrm{pg} / \mathrm{ml}$ ) but a significant reduction in peak $E$ response was observed (E, $244 \pm 42 \mathrm{pg} / \mathrm{ml}, P<0.05)$. HR and BP responses to hypoxemia were generally similar to control animals though there appeared to be a brief 1-3-min lag period between the nadir of the bradycardia and the peak of the BP response. We conclude that the generalized chemical sympathectomy after $6 \mathrm{HD}$ administration in the fetal lamb in utero is useful in evaluating the interaction of the autonomic nervous system and adrenal medullary function on the regulation of the fetal cardiovascular system.
\end{abstract}

\section{Abbreviations}

BP, blood pressure

E, epinephrine

6HD, 6-hydroxydopamine

HR, heart rate

$\mathrm{NE}$, norepinephrine

NS, not significant

Hypertension and bradycardia characterize the fetal cardiovascular response to hypoxemia and are mediated by increases in sympathetic and parasympathetic tone $(2,3,14,16,23)$. The increased level of sympathetic tone appears to be the result of synergism between elevated adrenergic neuronal activity and circulating catecholamines $(4,13,15)$. Previous investigations in normoxemic fetal lambs have shown that $\mathrm{NE}$ is the predominant circulating catecholamine whereas $\mathrm{E}$ is present in relatively low concentrations $(4,5,13,15)$. Under hypoxemic conditions, NE levels rise 8-10-fold whereas plasma $\mathrm{E}$ increases approximately 50 -fold $(8,15)$. Additionally, increased activity in the sympa- thetic nerves supplying systemic arteriolar resistance vessels may augment further the degree of catecholamine-mediated vasoconstriction. Nevertheless, the relative contributions of both adrenergic neuronal tone and humoral catecholamines to the overall compensatory sympathetic response of the hypoxic fetus remains unclear.

Sympathectomy has often been used to study the activity of the sympathetic nervous system. Comline and Silver $(4,5)$ have shown that splanchnic denervation of the fetal adrenal glands results in decrease in E secretion; however, the sympathectomy thus achieved was limited to the adrenal glands alone and had no effect on overall sympathetic neuronal tone. Furthermore, these studies were performed in exteriorized fetal lambs under pentobarbital anesthesia, both of which may substantially alter cardiovascular and sympathetic activity (12). Recently, 6HD has been shown to produce complete chemical sympathectomy in several adult mammalian species by depleting sympathetic nerve terminals of $\mathrm{NE}$ and selectively damaging the terminal adrenergic nerve fibers for a prolonged period $(6,9,11,22)$.

The present investigation was undertaken to examine the effect of chemical sympathectomy with $6 \mathrm{HD}$ on resting $\mathrm{HR}, \mathrm{BP}$, and plasma catecholamine concentrations in normoxemic fetal lambs in utero and to evaluate the response of the sympathectomized fetus to hypoxemia.

\section{MATERIALS AND METHODS}

Ten fetal lambs with time-dated gestations were operated between $105-115 \mathrm{~d}(0.70-0.77$ gestation) as previously described (14-16). Briefly, the ewes were sedated with acepromazine and low spinal anesthesia was administered. Through a small hysterotomy, polyvinyl catheters were inserted into the fetal carotid artery, jugular vein, trachea, and amniotic cavity and an inflatable silicone rubber cuff constrictor was placed around the umbilical cord. The catheters and actuating tubing of the constrictor were tunneled subcutaneously and exteriorized to a cloth pocket sewn to the ewe's flank. Penicillin and kanamycin were administered intraoperatively and daily for $1 \mathrm{wk}$ postoperatively. The animals were permitted to recover for $1 \mathrm{wk}$ before investigation.

Fetal carotid arterial blood gases and $\mathrm{pH}$ were measured by a Radiometer BMS-3 blood gas analyzer. Arterial, central venous, tracheal, and intraamniotic pressures were measured by Statham $23 \mathrm{Db}$ pressure transducers and continuously recorded on a Beckman R 411 polygraph. The fetal HR was displayed by a cardiotachometer triggered by the arterial pressure pulse.

Increasing doses of $6 \mathrm{HD}$ were administered to the fetus by daily intravenous infusion for $5 \mathrm{~d}$ until a total dose of 60-70 $\mathrm{mg} / \mathrm{kg}$ was reached. Fetal body weight was estimated from the gestational age using the data of Barcroft (1). Each daily dose of $6 \mathrm{HD}$ was administered over $1 \mathrm{~h}$ by continuous infusion during 
which time HR and BP were monitored. The initial dose was 1$3 \mathrm{mg} / \mathrm{kg}$ followed by progressive daily increases to $5,10,20$, and $25-30 \mathrm{mg} / \mathrm{kg}$. A supplemental dose of $20 \mathrm{mg} / \mathrm{kg}$ was given every 7-10 d thereafter in order to insure continuation of effective sympathectomy. The adequacy of sympathectomy was evaluated by the intravenous administration of tyramine $(100-400 \mu \mathrm{g} / \mathrm{kg})$ before and after completion of the 6HD dose schedule (9). The hematocrit was measured before and after each daily dose for the first three animals in order to determine whether hemoconcentration had occurred (9). Because no change in hematocrit was observed, this measurement was discontinued for the remainder of the study group. Carotid arterial blood samples ( 0.6 $\mathrm{cm}^{3}$ ) were obtained for catecholamine determination before and after each daily $6 \mathrm{HD}$ infusion.

After the completion of the 6HD dose schedule, a 24-h recovery period preceded the evaluation of hypoxemia. Fetal arterial $\mathrm{PO}_{2}$ was lowered to $10-12$ torr by gradual constriction of the umbilical cord over 15-30 min during which time the ewe breathed room air $(14,15)$. Arterial blood specimens for catecholamine analysis were obtained during a pre-hypoxia control period and during maximal hypoxia. The blood samples were added to EGTA and glutathione $(12 \mu \mathrm{L})$, centrifuged, and the plasma stored at $-50^{\circ} \mathrm{C}$ for later analysis. After release of the umbilical constrictor the animals were permitted to recover for $48 \mathrm{~h}$ before the next hypoxia study.

Plasma catecholamines were measured using a highly sensitive tritiated radioenzymatic assay $(18,19)$ available in kit form (CatA-Kit ${ }^{\mathrm{TM}}$, Upjohn Diagnostics). Briefly, the method utilizes Catechol-O-methyltransferase to transfer a tritiated methyl group to $\mathrm{NE}$ and $\mathrm{E}$. The resulting tritiated normetanephrine and metanephrine were separated by thin layer chromatography and the radioactivity of each determined by a scintillation counter. Because only NE and E were assayed and plasma dopamine specifically excluded, there was no potential for cross-reactivity with the administered 6HD. The technique is sensitive to $5 \mathrm{pg}$ for NE and $3 \mathrm{pg}$ for E per $50 \mu \mathrm{L}$ sample. The data were stored by a Hewlett-Packard desk-top computer (Model 9845B) and analyzed using Student's $t$ test.

\section{RESULTS}

Chemical sympathectomy with $6 \mathrm{HD}$ was performed in eight of the 10 fetal lambs. Normoxemic and hypoxemic cardiovascular and catecholamine measurements were obtained from the two non-sympathectomized animals and were used to supplement our observations in 10 previously reported fetuses (15). A total of 34 non-sympathectomy hypoxia experiments were performed in 12 control animals and were compared with 16 experiments performed in the eight fetuses pretreated with $6 \mathrm{HD}$. Resting fetal HR, BP, and blood gases were stable in all animals included in the study ( $\mathrm{pH} \geq 7.35, \mathrm{PO}_{2} \geq 20$ torr, $\mathrm{PCO}_{2} \leq 45$ torr).

Acute Effects of $6 H D$. The intravenous infusion of the initial, small dose $(1-3 \mathrm{mg} / \mathrm{kg})$ of $6 \mathrm{HD}$ produced a striking sympathetic response manifested by hypertension and tachycardia (Fig. 1). This increase in HR and BP persisted for 30-60 min after 'completion of the infusion and thereafter gradually declined. Twenty-four hours later, before the administration of each subsequent dose of $6 \mathrm{HD}$, fetal $\mathrm{HR}$ and BP were within the normal range. The 5 and $10 \mathrm{mg} / \mathrm{kg}$ doses were generally well tolerated and produced lesser increases in HR and BP. With doses of 20 and $25 \mathrm{mg} / \mathrm{kg}$, two animals were noted to have short bursts of tachycardia of up to 300 beat/min and/or frequent premature beats approximately two-thirds of the way through the infusion period. These rhythm disturbances, which were probably paroxysmal supraventricular tachycardia and atrial and/or ventricular premature beats, subsided after briefly stopping the drug. The $6 \mathrm{HD}$ was then restarted at a slower infusion rate without difficulty.

Plasma catecholamine concentrations were normal before each daily $6 \mathrm{HD}$ dose but rose in response to each drug infusion. The increase in NE tended to be highest after the first, small 6HD dose and was generally lower after completion of the final dose (initial NE, $1367 \pm 368(\bar{x} \pm \mathrm{SE}) \mathrm{pg} / \mathrm{ml}$ versus final, $552 \pm 214$ $\mathrm{pg} / \mathrm{ml}$ ); however, these differences were not statistically significant. The $E$ responses showed even less of a tendency to be related to the dose schedule with an initial peak response averaging $76 \pm 14 \mathrm{pg} / \mathrm{ml}$ and a final dose response of $129 \pm 62 \mathrm{pg} /$ $\mathrm{ml}$ (NS).

The adequacy of sympathectomy was tested by the intravenous administration of tyramine. Before sympathectomy, the fetal cardiovascular response to tyramine consisted of a prompt increase in BP and decrease in HR (Fig. 2). This response was completely abolished after $6 \mathrm{HD}$ treatment. It is noteworthy that plasma NE and $\mathrm{E}$ concentrations were not affected by tyramine administration either before or after sympathectomy.

Cardiovascular and catecholamine responses to hypoxemia. The cardiovascular and catecholamine responses of both the control group and the sympathectomized fetuses to umbilical cord constriction are summarized in Table 1. During normoxemic baseline conditions, arterial oxygen tension and HR were
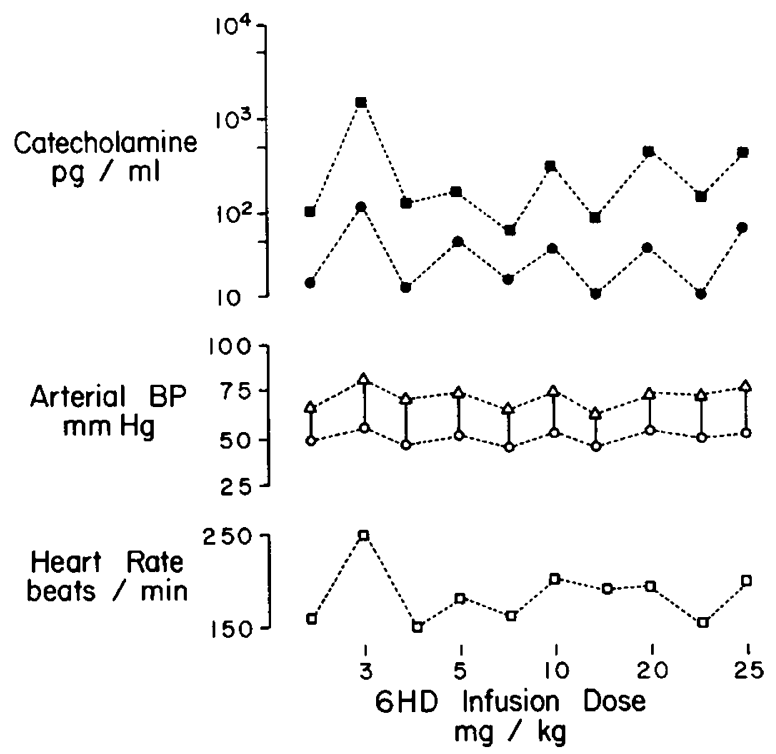

Fig. 1. The catecholamine and cardiovascular responses to daily infusions of 6-hydroxydopamine (6HD) in a fetus at 0.77 gestation. The responses to the initial, small dose of $6 \mathrm{HD}$ tended to be greater than that following subsequent doses $(\square$, norepinephrine; $\bullet$, epinephrine; $\Delta$, systolic blood pressure (BP); $\mathrm{O}$, diastolic BP; and $\square$, heart rate).

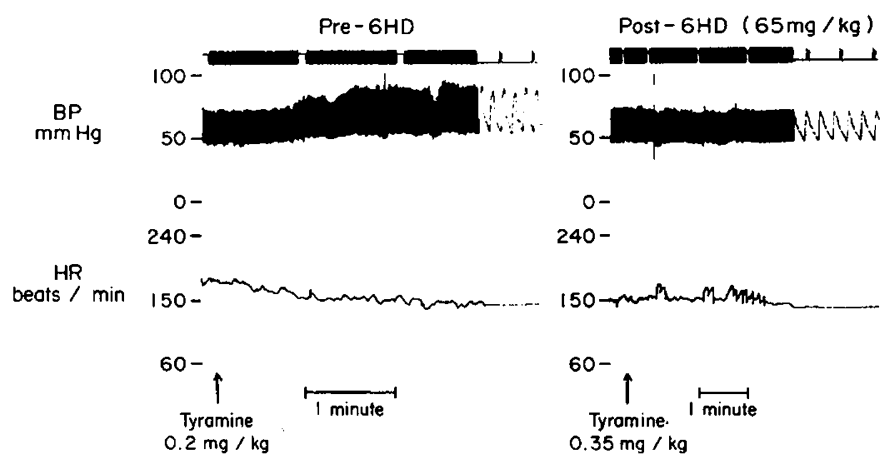

Fig. 2. Fetal cardiovascular responses to tyramine before and after chemical sympathectomy. Before 6-hydroxydopamine $(6 \mathrm{HD})$ treatment, tyramine produced and increase in blood pressure (BP) and decrease in heart rate (HR) within $30-60 \mathrm{~s}$. After $6 \mathrm{HD}(65 \mathrm{mg} / \mathrm{kg}$ total) there is no change in either HR or BP after $350 \mu \mathrm{g} / \mathrm{kg}$ of intravenous tyramine, confirming the adequacy of sympathectomy. 
Table 1. Fetal cardiovascular and catecholamine responses to hypoxemia after chemical sympathectomy* $\dagger$

\begin{tabular}{lcccccc}
\hline Condition & $n \ddagger$ & $\begin{array}{c}\mathrm{PO}_{2} \\
\text { (torr) }\end{array}$ & $\begin{array}{c}\mathrm{HR} \\
(\text { beat } / \mathrm{min})\end{array}$ & $\begin{array}{c}\mathrm{BP} \\
(\mathrm{mm} \mathrm{Hg})\end{array}$ & $\begin{array}{c}\mathrm{NE} \\
(\mathrm{pg} / \mathrm{ml})\end{array}$ \\
\hline $\begin{array}{l}\text { Baseline } \\
\text { Controls }\end{array}$ & 12 & $22.6 \pm 0.4$ & $161 \pm 4$ & $\frac{68 \pm 1}{45 \pm 1}$ & $259 \pm 25$ & $21 \pm 4$ \\
$6 \mathrm{HD}$ & 8 & $22.1 \pm 0.7 \|$ & $168 \pm 6 \|$ & $\frac{73 \pm 2 \S}{49 \pm 1}$ & $313 \pm 73 \|$ & $39 \pm 15 \|$ \\
$\begin{array}{l}\text { Hypoxia } \\
\text { Controls }\end{array}$ & 12 & $11.4 \pm 0.5$ & $100 \pm 4$ & $\frac{86 \pm 3}{58 \pm 2}$ & $2416 \pm 419$ & $2017 \pm 749$ \\
6 HD & 8 & $12.6 \pm 0.3 \|$ & $118 \pm 4 \|$ & $\frac{86 \pm 3}{61 \pm 2}$ & $1550 \pm 261 \|$ & $244 \pm 42 \S$ \\
\hline
\end{tabular}

*Abbreviations: $\mathrm{Po}_{2}$, carotid arterial oxygen tension; $\mathrm{HR}$, heart rate; $\mathrm{BP}$, arterial blood pressure; NE, norepinephrine; E, epinephrine; $6 \mathrm{HD}$, pretreatment with 6-hydroxydopamine.

$\dagger$ Data expressed as mean \pm SEM.

$\ddagger n$, number of animals.

$\S P<0.05$

\| Not significant.

similar in both groups. Arterial blood pressure, however, was slightly but significantly $(P<0.05)$ higher in the sympathectomized animals. This might have resulted from the slightly higher baseline plasma catecholamine concentrations in sympathectomized group.

After the decline in arterial oxygen tension, control animals demonstrated a rapid decrease in HR and increase in systemic arterial pressure $(P<0.01)$. Highly significant increases in both $\mathrm{NE}$ and $\mathrm{E}$ levels were noted concurrently $(P<0.01)$. N concentrations rose to $2416 \pm 419 \mathrm{pg} / \mathrm{ml}$ and peak plasma $E$ levels averaged $2017 \pm 749 \mathrm{pg} / \mathrm{ml}$, which represent increases of 10 -fold and 100 -fold, respectively.

The sympathectomized fetuses responded to hypoxemia somewhat differently from the control group (Fig. 3). HR fell promptly as arterial $\mathrm{PO}_{2}$ declined to $12.6 \pm 3$ torr (Hypoxia " 1 ") and was similar to control animals. The rise in blood pressure tended to be more gradual and reached its peak approximately 1-3 min after the initial decline in HR (Hypoxia "2"). During this 1-3min period, HR began to gradually increase from its original nadir and parallel the increase in blood pressure. Throughout this time, however, arterial $\mathrm{PO}_{2}$ remained unchanged. The gradual rise in BP did not appear to be the result of a concomitant further increase in plasma NE concentration because the latter was essentially stable during this 1-3 min period of hypoxia. Epinephrine levels, however, fell modestly but significantly $(P<$ 0.05 ) from the initial hypoxemic concentration to that obtained during the highest BP. For the purpose of comparison with the control group, however, the data obtained in the sympathectomized fetuses during the first and second hypoxic periods were pooled (Table 1 and Fig. 4).

Plasma NE and E concentrations in the sympathectomized fetal lambs increased significantly above baseline values during hypoxemia $(P<0.05)$. When these values were compared with non-sympathectomized controls important difference were noted. The peak NE values tended to be lower in the 6HD animals $(6 \mathrm{HD}, 1550 \pm 419 \mathrm{pg} / \mathrm{ml})$, but the difference was not statistically significant. In contrast, peak E levels were significantly lower $(P<0.05)$ in the sympathectomized group and averaged approximately $1 / 8$ the concentrations in control fetuses $(6 \mathrm{HD}, 244 \pm 42$ versus control $=2017 \pm 749)$. It is noteworthy that in several control animals the hypoxemic NE and E concentrations exceeded $10,000 \mathrm{pg} / \mathrm{ml}$. The highest NE level observed in a sympathectomized fetus was $7237 \mathrm{pg} / \mathrm{ml}$ whereas the maximum E level noted was only $835 \mathrm{pg} / \mathrm{ml}$. Chemical sympathectomy with $6 \mathrm{HD}$ appears to have a major impact on the plasma $\mathrm{E}$ response to hypoxemia. The NE response, however, is only mildly, but not significantly, lowered by sympathetic neuronal blockade.

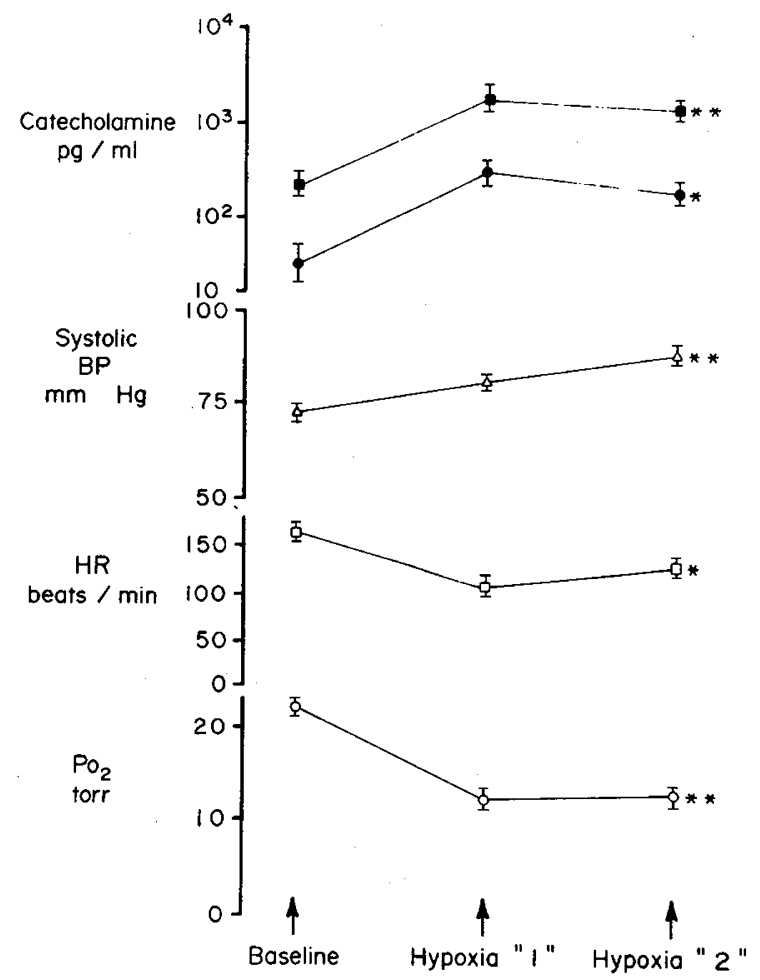

Fig. 3. Catecholamine and cardiovascular responses to hypoxemia in sympathectomized fetal lambs. The decline in heart rate (HR) in response to hypoxemia was prompt and similar to controls. Blood pressure (BP) increased more gradually, however. Hypoxia "1" represents measurements made as soon as HR reached its lowest point. One to three minutes later BP reached its maximum (Hypoxia " 2 ") and a second series of measurements obtained. ( $\mathbf{\square}$, norepinephrine; $\boldsymbol{\bullet}$, epinephrine; $\triangle$, systolic blood prssure (BP); $\square$, heart rate (HR); $O$, arterial $\mathrm{PO}_{2}$ ) $* P<0.05$ and ** NS for comparisons between Hypoxia " 1 " and "2."

\section{DISCUSSION}

The sympathetic response to hypoxemia in the fetal lamb represents the net effect of increased adrenergic neuronal activity and circulating catecholamines. Utilizing splanchnic nerve sections, Comline and Silver $(4,5)$ have shown that sympathetic innervation of the adrenal gland is an important mediator of $\mathrm{E}$ release in the late gestation fetus; however, concern persists about these findings because of the acute nature of these experiments 


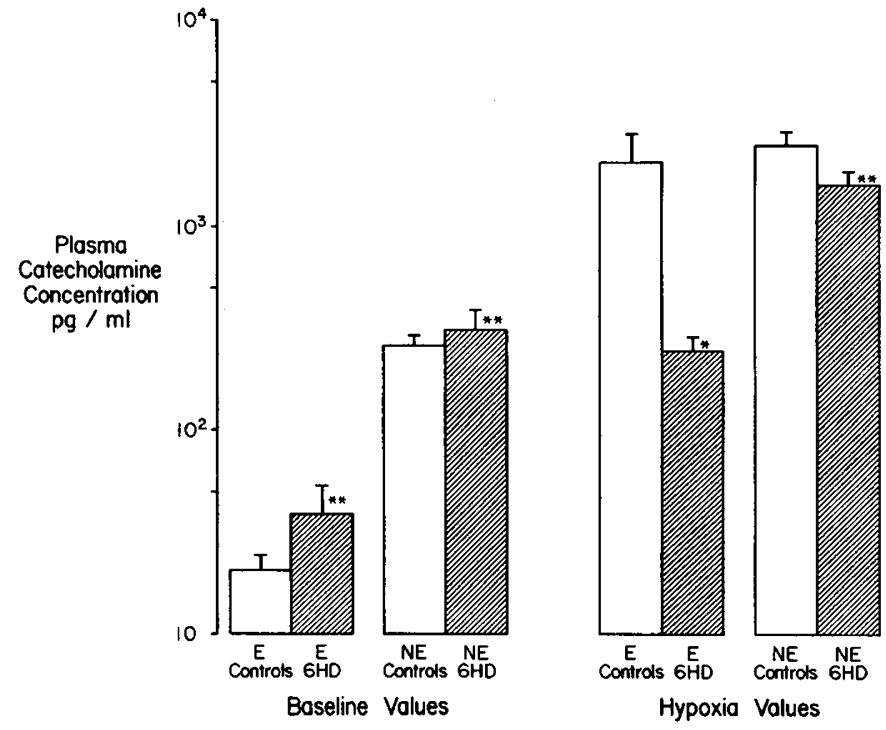

Fig. 4. Plasma catecholamine concentrations in control and sympathectomized fetus are compared during normoxemic and hypoxemic conditions. Baseline epinephrine (E) and norepinephrine (NE) values are slightly higher than controls, but the differences are not significant. Catecholamines in 6HD animals rise during hypoxemia. Peak E concentrations are significantly lower than control whereas NE levels are not significantly less than hypoxemic controls $\left({ }^{*} P<0.05\right.$ and $\left.{ }^{* *} \mathrm{NS}\right)$.

performed in exteriorized and anesthetized fețal lambs (12). Furthermore, little information exists about the response of fetal lambs in utero to hypoxemia after a more generalized reduction in sympathetic neuronal tone.

Chemical sympathectomy. Surgical sympathectomy has serous limitations because it often requires extensive surgical manipulation and is usually limited to individual organs. Drugs that deplete norepinephrine, such as reserpine, have the disadvantage of interfering with functions unrelated to the sympathetic nervous system (9). The synthetic catecholamine, $6 \mathrm{HD}$, is closely related to the naturally occurring neurotransmitters and has been shown to produce prolonged depletion of NE from postganglionic sympathetic nerve terminals by altering the binding sites (21). It also selectively damages the adrenergic nerve terminals for up to 2-4 wk after treatment (11). The acute and chronic effects of 6HD have been extensively studied in adult rats $(6$, 22 ), cats (11), and dogs (9) but little data is available about its effects on sympathetic activity in the fetus.

Cumulative doses of $50 \mathrm{mg} / \mathrm{kg}$ of $6 \mathrm{HD}$ have been used in dogs to achieve complete sympathectomy $(9,20)$; however, intravenous infusion of $5 \%$ Dextran has been necessary to maintain adequate plasma volume and present circulatory collapse during these acute studies in which the 6HD was administered over 4$10 \mathrm{~h}$. The rapid decrease in plasma volume was attributed to the very high levels of circulating catecholamines released by $6 \mathrm{HD}$ (9). We have attempted to minimize the acute effect of $6 \mathrm{HD}$ on blood volume by infusing progressively larger doses over $5 \mathrm{~d}$ until a total of $60-70 \mathrm{mg} / \mathrm{kg}$ was reached. Unlike the more rapid infusions in dogs, no change in hematocrit was observed in the fetal lamb using this dose schedule. Supplemental doses of 20 $\mathrm{mg} / \mathrm{kg}$ of $6 \mathrm{HD}$ were given every $7-10 \mathrm{~d}$ based upon the observation that the damage to postganglionic sympathetic nerve terminals persists for $2-4 \mathrm{wk}$ (11).

The initial doses of 6HD produced a striking adrenergic discharge consisting of increases in plasma NE and $\mathrm{E}$ concentrations accompanied by hypertension and tachycardia. Similar responses have been observed in adult animals and appear to be the result of displacement of NE from the sympathetic nerve ending by $6 \mathrm{HD}$ (9). After cumulative doses above $10-15 \mathrm{mg} / \mathrm{kg}$, however, sympathetic fibers are probably depleted of most of their endogenous NE stores and the remaining sympathetic activity may be secondary to a direct stimulatory action of high doses of $6 \mathrm{HD}$ on both peripheral alpha-adrenergic receptors and adrenal medullary cells, which release catecholamines into the circulation (9).

Tyramine administration has been used previously to verify the adequacy of chemical sympathectomy $(9,22)$. Additional studies have corroborated the completeness of sympathectomy by documenting marked depletion of tissue stores of NE for up to 4 wk after treatment $(9,11,20)$. The hypertension and mild reflex bradycardia observed after tyramine administration in fetal lambs before chemical sympathectomy were eliminated after completion of the 6HD dose schedule. Thereafter, weekly testing with tyramine confirmed the continuation of effective sympathectomy.

Normoxemic responses to chemical sympathectomy. Despite the loss of peripheral adrenergic innervation after $6 \mathrm{HD}$ administration, fetal $\mathrm{HR}$ and BP were adequately maintained during resting, normoxemic conditions. In fact, BP was slightly higher in the sympathectomized animals than in non-sympathectomized controls. Similar findings in other species have been attributed to compensatory hyperfunction of the adrenal medulla (20) with an increase in the synthesis and turnover of catecholamines (17). But, in another study (7) total catecholamine content of the adrenals remained unchanged. It has been postulated, therefore, that the rate of catecholamine secretion into the circulation is increased in order to compensate for the reduction in peripheral adrenergic neuronal tone (20). The slight increase in baseline plasma NE and E observed in sympathectomized fetuses supports this proposition. Furthermore, the mild elevation in resting BP may have been due, in part, to hypersensitivity of adrenergic receptors, thereby potentiating the cardiovascular effects of circulating catecholamines. Such receptor hyperactivity after 6HD administration has been observed by Gauthier $e t$ al. $(10)$ in the dog.

Response to hypoxemia after sympathectomy. Plasma catecholamines in the late gestation fetal lamb rise dramatically in response to hypoxemia $(4,8,13,15)$. Previously reported data from our laboratory (15) have been expanded by the present study and confirm a 10-fold increase in NE levels and approximately 50-100-fold increase in E concentrations. Comline and Silver $(4,5)$ have demonstrated that NE release during hypoxemia is mediated predominantly by a direct effect of low arterial $\mathrm{PO}_{2}$ on the adrenal medulla whereas $\mathrm{E}$ secretion in the late gestation fetus appeared to be mediated by increased sympathetic activity via the splanchnic nerve. Our observations in chemically sympathectomized fetuses corroborate these mechanisms. NE levels in sympathectomized animals rose considerably during hypoxia and were not significantly different from hypoxemic controls. In contrast, plasma $\mathrm{E}$ levels in hypoxemic fetuses pretreated with $6 \mathrm{HD}$ were significantly lower than in the control group.

The sympathectomized fetal lamb appears capable of maintaining appropriate HR and BP responses to hypoxemia. The vagally mediated decline in HR occurs promptly with the onset of significant hypoxemia and, as we have demonstrated previously, is not merely the result of a baroreflex phenomenon (14). The rise in BP, however, appears to be somewhat more gradual in the chemically sympathectomized fetus. A lag period of $1-3$ min is often present between the nadir of the bradycardia and the peak in hypertension. One possible mechanism to explain this observation is that a short time period is necessary for circulating plasma catecholamines to reach and stimulate peripheral adrenergic receptors. The immediate, primary phase of vasoconstriction may reflect direct adrenergic neuronal innervation followed by a secondary phase of alpha-receptor stimulation by increased plasma NE and $E$ released by the adrenal gland. The hypertensive response to hypoxemia in the fetus is indeed likely to be the result of a synergism between sympathetic neuronal activity and circulating catecholamines. A similar relationship between the peripheral sympathetic nervous system and the adrenal medulla has been proposed by DeChamplain and $\mathrm{Na}-$ 
deau (7) for the maintenance of cardiovascular tone in adult animals. Furthermore, the inter-relationship of adrenergic neuronal and humoral elements also occurs within the adrenal gland itself because sympathetic innervation of the adrenal medulla appears to be essential for the proper discharge of $E$ into the circulation during hypoxia. Before the development of the sympathetic nerve supply to the adrenal gland during the final quarter of gestation, the hypertensive response of the fetus to hypoxia appears to be regulated adequately by the interaction of the sympathetic nervous system and adrenal medullary NE release $(14,15)$.

\section{REFERENCES AND NOTES}

1. Barcroft, J.: Researches on prenatal life. (Blackwell, Oxford, 1946).

2. Born, G. V. R. Dawes, G. S., and Mott, J. C.: Oxygen lack and autonomic neurons control of the faetel circulation in the lamb. J. Physiol. (London), 134: 149 (1956).

3. Cohen, H. E., Sacks, E. J., Heymann, M. A., and Rudolph, A. M.: Cardiovascular responses to hypoxemia and acidemia in fetal lambs. Am. J. Obstet. Gynecol., 120: 817 (1974).

4. Comline, R. S. and Silver, M.: The release of adrenaline and noradrenaline from the adrenal glands in the fetal sheep. J. Physiol., 156: 424 (1961).

5. Comline, R. S., Silver, I. A., and Silver, M.: Factors responsible for the stimulation of the adrenal medulla during asphyxia in the faetal lamb. $J$. Physiol., 178: 211 (1965).

6. DeChamplain, J.: Degeneration and regrowth of adrenergic nerve fibers in the rat peripheral tissues after 6-hydroxydopamine. Can. J. Physiol. Pharmacol., 49: 345 (1971).

7. DeChamplain, J. and Nadeau, R. A.: 6-hydroxydopamine, 6-hydroxydopa and degeneration of adrenergic nerves. Fed. Proc., 30: 877 (1971).

8. Eliot, R. J., Klein, A. H., Glatz, T. H., Lam, R. Palmer, S., Padgett, D., and Fisher, D. A.: Norepinephrine, epinephrine and dopamine levels in response to hypoxia in neonatal lambs. Clin Res., 27: 124A (1979).

9. Gauthier, P., Nadeau, R., and DeChamplain, J.: Acute and chronic cardiovascular effects of 6-hydroxydopamine in dogs. Circ. Res., 31: 207 (1972).

10. Gauthier, P., Nadeau, R., and DeChamplain, J.: Cardiovascular reactivity in the dog after chemical sympathectomy with 6-hydroxydopamine. Can. J. Physiol. Pharmacol., 52: 590 (1974).

11. Haeusler, G., Haefely, W., and Thoenen, H.: Chemical sympathectomy of the cat with 6-OH-DA. J. Pharmacol. Exp. Ther., 170: 50 (1969).

12. Heymann, M. A. and Rudolph, A. M.: Effect of exteriorization of the sheep fetus on its cardiovascular function. Circ. Res., 21: 741 (1967).

13. Jones, C. T. and Robinson, R. O.: Plasma catecholamines in faetal and aduit sheep. J. Physiol., 248: 15 (1975).

14. Lewis, A. B., Donovan, M., and Platzker, A. C. G.: Cardiovascular responses to autonomic blockade in hypoxemic fetal lambs. Biol. Neonate, 37: 233 (1980).

15. Lewis, A. B., Evans, W. N., and Sischo, W.: Plasma catecholamine responses to hypoxemia in fetal lambs. Biol. Neonate, $41: 115$ (1982)

16. Lewis, A. B., Nestor, L., Dahms, B., and Platzker, A. V. B.: Cardiovascular responses to autonomic blockade in brain-injured fetal lambs. Biol. Neonate, 34: 97 (1978).

17. Mueller, R. A.: Effect of 6-hydroxydopamine on the synthesis and turnover of catecholamines and protein in the adrenal. In: T. Malmfors and $H$. Thoenen, Eds.: 6-Hydroxydopamine and Catecholamine Neurons. pp, 291-300 (North Holland Publishing Company, 1971).

18. Passon, P. G. and Peuler, J. D.: A simplified radiometric assay for plasma norepinephrine and epinephrine. Anal. Biochem., 51:618 (1973).

19. Peuler, J. D. and Johnson, G. A.: A sensitive radioenzymatic assay of plasma catecholamines: Initial studies in supine normotensive subjects. Clin. Res. 23: 474A (1975).

20. Porlier, G. A., Nadeau, R. A., De Champlain, J., and Bichet, D. G.: Increased circulating plasma catecholamines and plasma renin activity in dogs after chemical sympathectomy with 6-hydroxydopamine. Can. J. Physiol. Pharmacol., 55: 724 (1977).

21. Porter, C. C., Totaro, J. A. and Stone, C. A.: Effect of 6-hydroxydopamine and some other compounds on the concentration of norepinephrine in the hearts of mice. J. Pharmacol. Exp. Ther., 140: 308 (1963).

22. Tranzer, J. P. and Thoenen, H.: Electron microscopic study of selective acute degeneration of sympathetic nerve terminals after administration of 6hydroxydopamine. Experimentia, 24: 155 (1968).

23. Vapaavouri, E. K., Shinebourne, E. A., Williams, R. L., Heymann, M. A., and Rudolph, A. M.: Development of cardiovascular responses to autonomic blockade in intact fetal and neonatal lambs. Biol. Neonate, 22: 177 (1973).

24. Requests for reprints should be addressed to: Dr. Alan B. Lewis, Division of Cardiology, Children's Hospital of Los Angeles, 4650 Sunset Blvd., P.O. Box 54700, Los Angeles, CA 90054-0700.

25. Funded in part by grants from the Kenneth $T$. and Eileen $L$. Norris Foundation and the Childrens Heart Foundation of Southern California.

26. The authors gratefully acknowledge the secretarial assistance of Ms. T. Rickerson in the preparation of this manuscript.

27. Received for publication December 7, 1982.

28. Accepted for publication June $15,1983$.

\title{
The Effects of Opiate Antagonism on Gonadotropin Secretion in Children and in Women with Hypothalamic Amenorrhea
}

\author{
S. E. SAUDER, ${ }^{(33)}$ G. D. CASE, N. J. HOPWOOD, R. P. KELCH, AND J. C. MARSHALL
}

Departments of Pediatrics and Communicable Diseases and Internal Medicine and the Reproductive Endocrinology Program, University of Michigan, Ann Arbor, Michigan, USA

\section{Summary}

The effects of opiate antagonism [naloxone infusion, $1 \mathrm{mg} /\left(\mathrm{m}^{2}\right.$. h)] on gonadotropin secretion were examined in four children (one female and three males: two late prepubertal and two pubertal; chronologic age, range 11.8-15.9 yr; bone age, range 8.5-13.5 yr) and in four women with hypothalamic amenorrhea (two at normal body weight and two at low body weight). Naloxone had no effect on daytime gonadotropin secretion in three children who were biologically the youngest in the group, two late prepubertal and one early pubertal [plasma luteinizing hormone (LH) $\bar{x} \pm$ SE: control day, $1.2 \pm 0.1$; control night, $4.5 \pm$ 0.4 ; and naloxone day, $1.3 \pm 0.1 \mathrm{mIU} / \mathrm{ml}$. In contrast, opiate blockade produced a slight but discernible increase in plasma LH in the child whose hypothalamic-pituitary-gonadal axis was the most mature, a boy at mid-puberty. Naloxone produced a striking increase in plasma $\mathrm{LH}$ in the amenorrheic women at normal body weight (LH, $\vec{x} \pm \mathrm{SE}$ : control day, $3.4 \pm 0.3$; control night, 7.0 \pm 1.0 ; and naloxone day, $7.4 \pm 0.7 \mathrm{mIU} / \mathrm{ml}$ ) as well as in those at low body weight ( $\mathrm{LH}, \bar{x} \pm \mathrm{SE}$ : control day, $3.5 \pm 0.3$; 